\title{
From the Editor of Sexuality and Disability: With Challenges... Come Opportunities
}

\author{
Sigmund Hough ${ }^{1}$
}

Published online: 3 November 2015

(C) Springer Science+Business Media New York 2015

The need to better understand, represent, advocate and provide quality healthcare in the field of sexuality and disability continues as an international challenge. This global endeavor brings the world a little closer to the issues and the ability to share the work and ideas on this journey. Most important with any challenge is the fact that our effort highlights that there are opportunities that surround us. Opportunities that can help others. Opportunities that can be undertaken. Opportunities to perhaps make the world a little better. And so we continue...

The journal of Sexuality and Disability remains a professional home for many, and a place of professional rejuvenation and exploration for still more. If you are new to the journal, we give to you a "BIG WELCOME" to participate as a reader, author, academician, clinician, educator, service provider, researcher, advocate, and individual or individuals seeking information. Over decades of contribution to the literature on sexuality and disability, we have been a part of the growth and understanding. Now most importantly, we continue to be a part of change in how we look and examine the topic, the need, and the response in terms of best practice-evidence based approaches. With the intelligence, experience, motivation and commitment from our authors, readership, peer reviewers and editorial board, and resources with guidance from the Springer Staff, our journal's mission continues to be strong and meaningful.

Sexuality and Disability continues to provide original impact articles addressing the mental health and medical aspects of sexuality in relation to rehabilitation, hospital, academic and community settings, publishing up-to-date articles, case studies, clinical practice reports, reviews, featured articles, historical articles, special grand rounds topics, brief research reports and survey data reports. Value benefit is provided to authors through worldwide electronic exposure and professional access, while readership gains from scholarly contributions to advance the field through research, best-practice and educational

Sigmund Hough

Sigmund_Hough@hms.harvard.edu

1100 Cummings Center, Suite 207, Beverly, MA 01915-6144, USA 
articles. The refined lens of individual contributions from the local and international community continues to deliver a wealth of information on the topic of sexuality and disability for the reader. Thank you for joining our professional community. 